\title{
The Systematic Evaluation of a Strategic Management Program in an Irish Institute of Technology
}

Deirdre Lillis

Technological University Dublin, deirdre.lillis@tudublin.ie

Follow this and additional works at: https://arrow.tudublin.ie/scschcomcon

Part of the Higher Education Administration Commons, and the Strategic Management Policy Commons

\section{Recommended Citation}

Lillis, D. (2005). The systematic evaluation of a strategic management program in an Irish Institute of Technology. Paper given at the 27th. Annual EAIR Forum, 28-31 August, Riga, Latvia. doi:10.1007/ s11233-006-9003-6

This Conference Paper is brought to you for free and open access by the School of Computer Sciences at ARROW@TU Dublin. It has been accepted for inclusion in Conference papers by an authorized administrator of ARROW@TU Dublin. For more information, please contact arrow.admin@tudublin.ie, aisling.coyne@tudublin.ie,gerard.connolly@tudublin.ie.

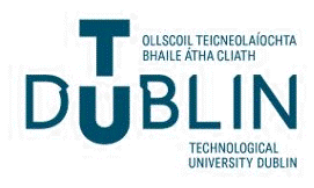


The Systematic Evaluation of a Strategic Management Program in an Irish Institute of Technology

Paper presented to the

27th ANNUAL EAIR FORUM

28 to 31 August 2005

Riga, Latvia

\section{Contact Details}

Deirdre Lillis, Head of Computing \& Mathematics Institute of Technology, Tralee

Tralee, Co. Kerry, Ireland

T+353 66 7191655, email: Deirdre.lillis@ittralee.ie, web: http://www.ittralee.ie

\section{$\underline{\text { Key words }}$}

1. Strategic Planning

2. Management

3. Quality

4. Institutional Performance Measures 5. Higher Education Research Design 


\begin{abstract}
Higher Education Institutes (HEIs) worldwide are investing significant resources in strategic planning and self-evaluation programs to improve institutional performance and to meet external stakeholder demands. Little empirical evidence exists however which demonstrates that these programs are effective in leading to improvements in institutional performance, let alone shed light on the reasons why. This paper reports on the systematic evaluation of the effectiveness of a Strategic Management program in an Irish HEI over a five year period in leading to improvements in institutional performance.
\end{abstract}

\title{
The Systematic Evaluation of a Strategic Management Program in an Irish Institute of Technology
}

Deirdre Lillis

\section{Context}

The Institute of Technology, Tralee (ITT) is a university-level institution in southwest of Ireland with courses in Business Studies, Engineering, Science \& Computing, with progression paths from Higher Certificate to Masters and Ph.D. ITT has approximately 3,500 students and 300 staff and is one of thirteen Institutes of Technology in Ireland (IOT) which can be loosely classified as being part of the "nonuniversity' sector of Higher Education internationally. Although an identical model to the IOTs does not exist, they exhibit some similarities with the Finnish AMKs, Dutch HBOs, French IUTs, German FHS and the Institutes of Technology in New Zealand.

ITT developed its first Strategic Plan in 2000 for the six year period 2000-2006 and was the first Institute in the IOT sector to do so. A revised Strategic Plan was developed for the period 2004-2007 as a result of the changing environment in which the Institute found itself. The term SP1 will be used in the sections that follow to include the period when the first Strategic Plan was developed and the subsequent implementation of the plan (2000-2004). Peer review panels in their reports have commended the advanced nature of the strategic planning process in ITT demonstrating that it is likely to be a good example of strategic planning in HE and will provide an information rich case study. This meets the criteria of an "intensity case" as defined by Patton, which though not unusual, from which much can be learned (Patton 2002:235).

It is important from the outset to clarify the author's role in SP1. She participated as a member of the group which developed the plan and has been a member of the Management Team throughout the lifetime of SP1 in various roles which included Strategic Program Office Manager, Delegated Authority project manager and currently as Head of Computing \& Mathematics. Given her involvement with the program being evaluated, every effort was made to eliminate potential bias by ensuring that both data sources and collection methods were triangulated. Where deemed necessary, a reminder of the author's involvement with the program will be included in the sections that follow to highlight any areas where potential bias may occur and to enable the reader to draw his/her own conclusions.

\section{Literature Review}

Despite the aim of the Bologna Declaration (EU 1999) of creating a common space and EU dimension for quality assurance in Higher Education (HE) in Europe, Teichler notes that research in HE is a relatively small field, estimating there are a few thousand researchers involved in systematic information gathering in HE in Europe with less than one thousand involved in full time research (Teichler 2003:47). Any empirical study contributing insights to the effectiveness of HE management is therefore a valuable addition to the literature.

Much of the literature in strategic management relates to the corporate sector (Mintzberg and Quinn 1998; 
Senge 1998; Johnson and Scholes 2002) with a smaller subset addressing the different driving forces of the public sector (Wilkinson and Monkhouse 1994; Lau 1999; Boyle and Flemming 2000; Pollitt and Bouckaert 2004). Some authors have looked at the unique characteristics of strategic management in HE specifically addressing strategic planning models, advantages, limitations and case studies (Conway, Mackay et al. 1994; Thys-Clement and Wilkin 1998; Pidcock 2001; Rowley, Lujan et al. 2001; Davies 2004; Tabatoni, Davies et al. 2004). Few have tackled the key question of the effectiveness of strategic planning programs in leading to improvements in institutional performance.

The benefits of strategic planning cited in the HE literature include its ability to capture the complexity of the organization as a whole and point it in a coherent direction; provide a platform to articulate the distinctive mission of a HEI; identify competitive advantage; and to increase awareness of and alignment to the external environment. It mobilises teams of staff into working together toward Institutional goals, gives a voice to all constituencies and often crosses traditional functional boundaries. The process itself can be more beneficial than the plan, particularly for first attempts. Some HEIs have found that it allows for transparent prioritisation and better resource utilisation, particularly relevant in an era of budgetary cutbacks. Strategic planning has its limitations also. It requires a leap of faith by senior management as it is necessarily based on empowerment of staff, which may be perceived as a loss of control and can lead to lack of commitment. There is a danger the plan becomes nothing more than a public relations tool to impress peer review panels and other stakeholders. There can also be a significant overhead involved in planning and review at the expense of normal activity, and the benefits are not immediately obvious

There appears to be growing consensus that it is an integral part of modern HE management (Thys-Clement and Wilkin 1998; Bayenet, Feola et al. 2000:67; Davies 2004). Increasingly HEIs find themselves having to align themselves to an external environment which is exerting more pressure and are faced with a choice between shaping and managing change internally or having it dictated by external forces (Skilbeck 2001). Pollitt \& Bouckaert urge caution when reacting to these trends citing the abundance of literature on management reforms of the public sector which postulate that the past is irrelevant. They call this the 'history is dead, everything is new' school of management thought. Instead they contend that there are limits and constraints to reform and that reform does not necessarily alleviate the problems of 'logical contradictions, bruised motivations, ergonomic constraints and problems of competing and divergent values' (Pollitt and Bouckaert, 2004).

An element of outright skepticism can be detected in some of the literature. Brunnson contends that an element of hypocrisy is inherent in all organizations - 'to talk in a way that satisfies one demand, to decide in a way that satisfies another and to supply products in a way that satisfies a third' (Brunsson, 1989). Pollitt \& Boukaert note the dearth of empirical studies which tackle the issue of evidence of improvements in effectiveness as a result of reform (Pollitt and Bouckaert, 2004). Birnbaum uses the term management fads to refer to innovations in HE management that are followed with exaggerated zeal for a brief period of time only to be abandoned subsequently without any real attempt to evaluate their effectiveness. He cites the example of Total Quality Management which was said to be used by $70 \%$ of all colleges in the US in 1994, but by 1997 it had transpired that only a dozen or so colleges had actually implemented it as part of core operations. Once the management innovation has been tried for some time, the private sector seeks concrete quantitative and qualitative data to evaluate it whereas the HE sector primarily relies on nonquantitative claims and subjective judgments. Birnbaum states that there are 'few published examples in the academic sector of attempts to assess the institutional consequences of a management fad through data that provide evidence either of organizational outcomes or of the satisfaction of users'. Given the exhaustive literature search undertaken in his study, this statement further validates the research questions of this study (Birnbaum, 2000).

\section{Strategic Management in the Public and Private sector}

In the private sector the strategic planning process starts by identifying the company's mission statement, which assumes it has the freedom to define its own purpose. By contrast in most cases the mission of public sector organizations including HEIs are predetermined, typically by legislative frameworks. This begs the question that if major changes in overall direction are not permitted, is strategic planning necessary or 
relevant for the HE sector? All long term planning in a HEI will therefore be within well defined pathways and goals, typically some variant of teaching, research and development work. In the private sector, while stakeholder views are considered, the mission statement typically articulates the benefits to the company. Public sector organizations exist to provide services to stakeholders and their mission statements reflect the benefits to a broad range of stakeholders.

Strategos is the greek word for 'the thinking and action of a general'. Private sector strategic planning models assume top-down executive control of the direction of the organization (Wilkinson and Monkhouse, 1994). Rowley et al argue strongly that this is not appropriate in a HE context and contend that a participatory approach, based on consensus building, is required to counteract a possible 'Power of Veto' situation occurring in academic departments (Rowley et al., 2001). Bayenet notes that without a modicum of support from academic departments it would be difficult if not impossible to put strategic plans in practice (Bayenet et al., 2000). Birnbaum concurs and suggests the HE sector has the ability to 'virtually adopt' a management innovation, given the decentralized autonomous structure of HEIs, without having it significantly affect core institutional processes. Bayenet notes that universities are often described as professional bureaucracies or organized anarchies with highly compartmentalized internal structures (ElKhawas, 1998, Mintzberg, 1998, Bayenet et al., 2000:67, Allen, 2003, Sporn, 2003). Davies notes that these structures exhibit a tendency to avoid confronting problems and exhibit a lack of accountability and defensiveness (Davies, 2004). Strongly collegial cultures and opposing cultures on the academic and central management/administrative side, often stemming from fundamentally different value systems and knowledge bases, can lead to barriers to introducing pan-Institute quality systems and strategic plans.

The lack of objective and universally accepted performance measures in HE is at odds with the measurable targets required in the objectives of a strategic plan (Davies, 2004). The driving force for change in HE is often meeting criteria imposed by a national quality assurance system (Brennan and Shah 1997). Davies notes that many HEIs would not have moved towards a strategic or quality culture without an external stimulus of some kind (Davies 2004). In addition, self-evaluation with peer review is an established and arguably successful quality assurance methodology in HE. The private sector does not have the equivalent of a peer review mechanism.

The literature review on this topic concluded that there was a paucity of studies on the effectiveness of strategic planning in leading to improvements in institutional performance in a HE context. It also concluded that there were sufficient differences between the sectors to legitimately ask the question whether a long term planning model designed for the corporate sector is necessary and appropriate in a HE setting.

\section{Research Methodology}

A distinctive contribution of this study to the literature is a methodological framework for the systematic evaluation of the effectiveness of strategic planning programs in a HE context. The post-positivist approach was chosen as an overall framework to focus what could otherwise be a broad and unwieldy topic and a hypothetic/deductive form of reasoning (analytic induction) was used on the basis of key themes which emerged from the literature review and preliminary research work. Elements of the phenomenological paradigm have been included in the research design. To increase the validity, reliability and generalisability of the results and to minimise bias, mixed mode methods of inquiry were used including document analysis, the participant observer technique and semi-structured/open ended interviewing.

Rossi et al's methodology for systematic evaluation of social programs was used (Rossi 2003). To be effective the program must lead to improvements and meet its goals and objectives. It is evaluated in terms of the underlying need it addresses, the appropriateness of its design, the degree to which it was implementation 'as-intended' and an assessment of its impact. A major component of the data collection process from the document record was the development of a Log of Issues where an issue is considered in its broadest sense (e.g. quality assurance initiative, campus development project, change to organizational structure etc). The complete document record was systematically analyzed from September 1997 to 
December 2004 to identify all new issues which arose during this period and to track progress made on each issue. This paper reports on the findings from the analysis of this Log of Issues.

\section{An assessment of the need for the strategic management program}

The origin of SP1 is not clear from the document record and it is important to understand what needs SP1 was intended to address. The hypothesis is that SP1 was developed to meet an internal and/or an external requirement is investigated here.

\section{Meeting an Internal Requirement}

A review of the minutes of the Governing Body, Academic Council and senior management team in the period 1997-2000 prior to the development of the plan (termed PreSP1) show that a high percentage of time was spent on topics which could be classified as operational strategy as per Johnson and Scholes categorization of strategic decisions (Johnson and Scholes, 2002). Advisory committees for specific areas (e.g. IT, library) met regularly but were limited in their scope. In the PreSP1 period it can be concluded that there was no structure or forum where issues of a strategic nature with Institute-wide scope with input from all constituencies were being discussed.

For quality assurance purposes, the Institute worked under the auspices of the National Council For Educational Awards (NCEA) in Ireland at the time of the development of SP1. The Institutional Review process was a quinnenial review of all Institute operations (including planning) ed by the NCEA. In a critique of self-evaluation processes, Thorn raises questions in relation to methodological shortcomings and the effectiveness of the Institutional Review process as a planning vehicle for a HEI (Thorn 2001). In any event, the Log of Issues indicates that the Institutional Review process was not implemented as intended as the deadlines for completing it slipped from October 1998 to December 2000 (27 months).

Another possibility in relation to the need for SP1 is that there was insufficient progress being made on issues arising during the PreSP1 period, resulting in dissatisfaction with the existing planning structures and processes. Using the Log of Issues described in Section 3, in total $n=72$ issues which the Institute was in control of were identified from the document record. Of these

- $31 \%$ were completed prior to the development of SP1

- $54 \%$ were subsequently included as objectives/strategies in SP1.

- $15 \%$ were not included in SP1.

No issue was actively retired or abandoned during this period, suggesting that a progress review mechanism was not in place.

In the PreSP1 period, $45 \%$ of all issues arising were either "Institute" issues requiring co-ordination across all Institute functions (18\%) or "Academic" issues requiring co-ordination of all three Schools/nine Departments (29\%). By way of example, Institute issues included quality structures and systems; internal audit function; submission for delegated authority. Academic issues included modularisation; student mentoring; course handbooks; student workload; open distance learning. The remaining issues could be specifically assigned to the Office of the Registrar (17\%), Development Office (22\%) and Office of the Secretary/Financial Controller (11\%). What is striking in this analysis is that only 2 issues (3\%) could be specifically assigned to an individual School of Study to progress. This raises questions as who was actually responsible for ensuring progress on Academic issues as responsibility was split between three Heads of School.

The fairest comparison is probably between Institute and Academic issues as both require co-ordination across functions. The analysis shows that substantially more progress was made on Institute wide issues. Taking the issues which were incomplete and which were subsequently included as objectives/strategies in SP1 demonstrates that by December 2003:-

- 5 of 7 Institute issues were successfully completed.

- 2 of 7 of Academic issues were successfully completed in all three Schools, one through an external intervention (HETAC policy). 
All Institute issues which were incomplete were subsequently included as objectives/strategies in SP1. Six Academic issues were incomplete and were not included as objectives/strategies in SP1.None of these issues were completed by December 2003.

It must be borne in mind at this point that is a broad and primarily quantitative measure only and no attempt has been made at this time to quantify and compare the amount of resources which were needed and allocated for each issue or the potential barriers to be addressed. The Log of Issues also demonstrates that within the individual Schools of Study, substantial progress was being made on course development, programmatic review and other initiatives but a significant portion of this was not captured in SP1. It could therefore be argued that SP1 was an incomplete reflection of the development work planned in the Institute. Where the School had individual responsibility for or control over an issue good progress was generally being made. The lack of progress on Academic issues may stem from the difficulties in coordinating three Schools of Study and/or a reluctance to resource School/Department issues arising from a fear of setting precedents. It is possible that resources allocated to one School would have to be replicated in all three. The reasons why this occurred will be a focus of further research. In any event, it points to particular difficulties in strategically aligning three Schools and to the lack of a formal structure or process whereby changes across all Schools/Departments could have been concurrently implemented. It also suggests that SP1 as implemented did not provide a mechanism to address this.

\section{Meeting an External Requirement}

The second possibility is that SP1 was developed in response to an external requirement.

\begin{tabular}{|l|l|l|l|}
\hline Academic Year of Origin & Governing Body & Academic Council & Executive Committee \\
& & & \\
\hline $1996 / 97$ (six months) & 0 & 8 & n/a \\
\hline $1997 / 98$ & 6 & 28 & n/a \\
\hline $1998 / 99$ & 10 & 8 & n/a \\
\hline $1999 / 00$ (six months) & 8 & 5 & 6 \\
\hline
\end{tabular}

Table 1 Academic Year of Origin of New Issues arising prior to the development of SPI

The 28 new issues in 1997/98 raised at the Academic Council stands out in this analysis and warrants further investigation, more than three times the number raised in other years. Of these 28 issues, more than $75 \%$ relate directly major planning or quality assurance processes. It is possible to associate this increased activity with the requirements of the Institutional Review process which was initiated that year which placed a high degree of importance on quality frameworks and planning. Coupled with the statement by the September 1998 Academic Council that it "Agreed that a Strategic Plan for the Institute was required for Institute Review", it suggests that SP1 was initiated to meet an external requirements.

\section{Program Impact Theory}

The purpose of developing or clarifying program theory is to determine in what way do program activities cause or effect changes. Rossi et al's model for articulating program theory is used here, which is based on the contention that outcomes which are a direct result of the program (proximal outcomes) must be evaluated if longer term outcomes (distal outcomes) are to lead to improvements. Distal outcomes are dependent on the attainment of proximal outcomes (Rossi et al., 2003). An action hypothesis links the program actions to proximal outcomes and a conceptual hypothesis links the achievement of proximal outcomes to distal outcomes. The program impact theory is developed from the perspective of capturing the program "as-intended". Program Impact Theory is represented in the following Logic Diagram: 


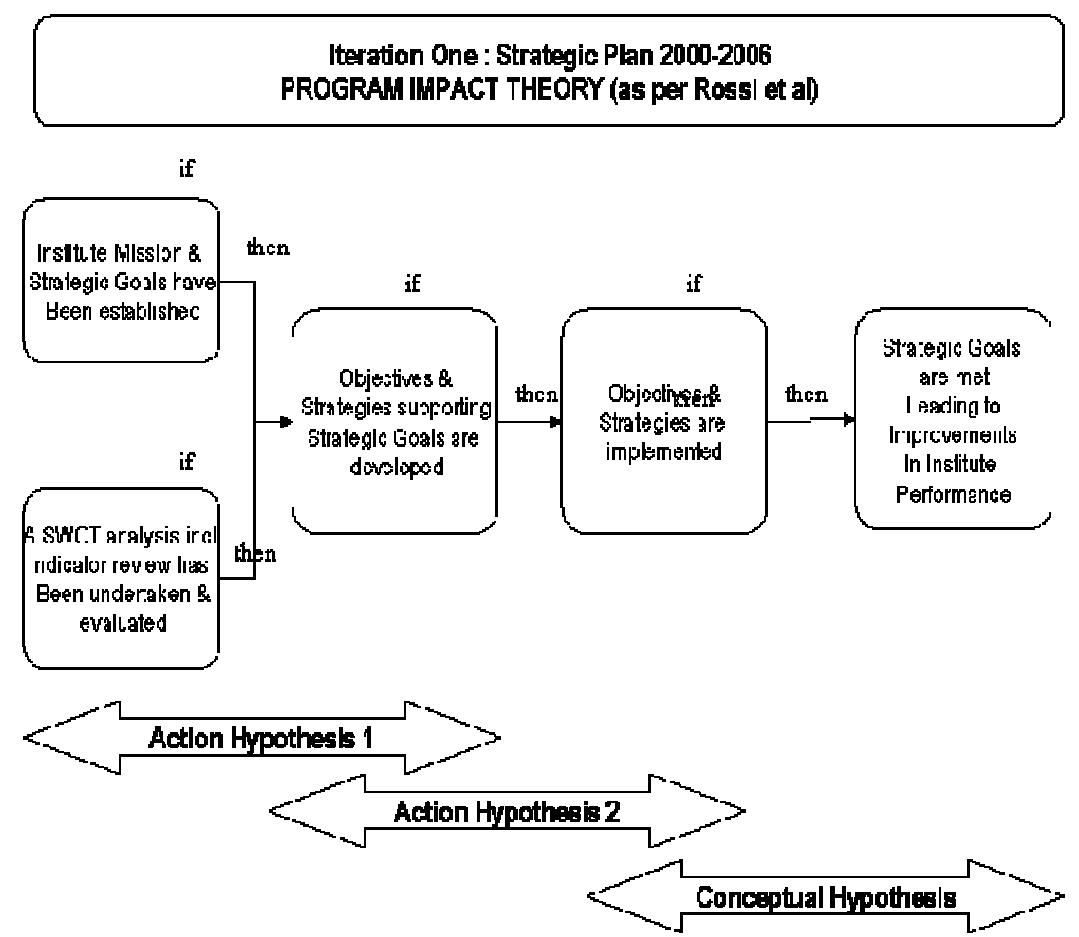

Figure 1 Program Impact Theory - Strategic Planning Program in IT Tralee 2000-2006

\section{Assessment of Program Process}

An assessment of program process was undertaken to determine the extent to which the program theory asintended was actually implemented as it is difficult to assess the impact of programs which have been partially or incorrectly implemented. The process assessment concentrates on the main program components identified as follows: mission \& goals; SWOT analysis; developing objectives and strategies and implementing objectives \& strategies. In conjunction with the program theory, this formed the basis for comparing the process "as intended" with the process "as implemented".

Mission and Goals: ITT's Mission Statement was adopted in 1997 as "To excel in teaching, research and development work, for the benefit of students, industry and the wider community". Thirteen strategic goals covering all aspects of the Institute's operations were developed through a consensus building approach and the goals relate either to the core activities as stated in the Mission Statement or to central support services, management processes or resources.

SWOT Analysis: A SWOT analysis summarises the key issues from the environment and the strategic capability of the organization that are most likely to impact on strategy development (Johnson and Scholes 2002). If the SWOT analysis has been effective there should be evidence in the resultant objectives and strategies that (i) internal strengths are being built on and weaknesses are being overcome and (ii)changes in the external environment have been considered through threats and opportunities. There is good evidence that strengths have been built upon in the resultant objectives. Most weaknesses have also been translated into objectives albeit less directly but a number of weaknesses identified in the Log of Issues were not included in the SWOT. Opportunities and threats were generally addressed. The Log of Issues captured external factors during the period 1997-2001 and the majority of these have been included in the SWOT.

Developing Objectives \& Strategies: In total 48 objectives were developed in support of the 13 strategic goals. All of these objectives are supported by one or more strategies, the vast majority of which are relevant to the objective. Of the $n=79$ issues identified in the PreSP1 document record, only $n=11$ were not subsequently included in the objectives/strategies of SP1. This illustrates that SP1 captured a significant percentage of the pertinent issues being discussed in the PreSP1 phase. There were $n=16$ objectives in SP1 which cannot be traced in the document record prior to SP1 which indicates that SP1 gave rise to fresh ideas and new thinking. $\mathrm{N}=7$ of these 16 new objectives relate directly to non-academic departments which 
suggests that SP1 gave these departments an opportunity for input to planning at an Institutional level which may not have been available previously.

A deficiency with some objectives was acknowledged in the ITT Delegated Authority self study report "some of the objectives had not been broken down into manageable strategies at planning stage"(ITT, 2004b:95) . In particular, a key objective in relation to target student numbers does not have meaningful strategies associated with it, although it could be argued that the majority of objectives in SP1 would support this objective. As per Pollitt \& Bouckaert's classification of Evaluability, the majority of objectives $(\mathrm{n}=42)$ are Level 1 (Operational) or Level 2 (Process) as would be expected. Six objectives are Level 3 (Capacity) or Level 4 (Ideological) which would make it very difficult to measure outcomes at a later stage(Pollitt and Bouckaert 2004). For the purposes of analysis the Marketing goal which had six objectives was condensed to one objective for consistency with similar goals in order not to skew results, giving a total of $n=43$ objectives.

Implementing Objectives \& Strategies: Managing strategic change as a set of logical processes including resource planning, organisational structure and design, and the principles of change management (Johnson and Scholes 2002). A meeting of the management team proposed the creation of 10 specific posts to implement the priority objectives of SP1 but relative to its size, and the fact that the Institute is not in control of its staffing or structures, this was unrealistic. It is also interesting that there is no recorded discussion in relation to downsizing/re-organising existing areas to meet new requirements (i.e. to work within existing resources). None of these proposed posts were subsequently established. With the benefit of hindsight, the Institute recognised this as an issue citing in its Self Evaluation Report that

"at this stage (mid-2001) we recognized that certain issues needed to be addressed and these included: the substantial additional workloads arising from strategic projects; additional physical and other resources relating to the objectives; some of the objectives had not been broken down into manageable strategies at planning stage; it was proving difficult to capture and monitor progress"(ITT, 2004a:95).

Implementing Control Systems: Midway through the plan, a Strategic Program Office was established on a part time basis, reporting to the Director. Its terms of reference included: map the objectives to project plans, monitor progress, liaise with project managers on a regular basis and provide training where required. (The author was responsible for the establishment of the Strategic Program Office). The international standard PMBOK - Project Management Body of Knowledge was used as a basis for a customized project management methodology (PMBOK 2004). The control systems which were put in place are as follows:-

\begin{tabular}{|l|l|l|}
\hline Process & As Intended & Actual Implementation \\
\hline Scope Statement & $\begin{array}{l}\text { The primary planning document for } \\
\text { each project, produced by the project } \\
\text { manager and his/her team. This } \\
\text { included a Gantt chart, resource plan, } \\
\text { communications plan, project team } \\
\text { composition, risk register. }\end{array}$ & $\begin{array}{l}\text { All project managers produced a scope } \\
\text { statement although the process by which it } \\
\text { was developed varied. Gantt charts were } \\
\text { produced for all projects, by either the SPO or } \\
\text { the project manager. }\end{array}$ \\
\hline Progress Status Reporting & $\begin{array}{l}\text { Regular Status reports from project } \\
\text { managers against the baseline project } \\
\text { plan. }\end{array}$ & $\begin{array}{l}\text { Overhead of monthly status reporting was too } \\
\text { much and system changed to quarterly } \\
\text { progress review meetings. }\end{array}$ \\
\hline Project Close Out & $\begin{array}{l}\text { Final review meeting with project } \\
\text { manager and Lessons Learned report } \\
\text { completed }\end{array}$ & Completed for five projects. \\
\hline Annual Progress Reports & $\begin{array}{l}\text { Progress report on the status of all } \\
\text { objectives highlighting current status, } \\
\text { progress achieved and issues } \\
\text { encountered }\end{array}$ & Produced in October 2002 and October 200 \\
\hline
\end{tabular}

Table 2 Control systems implemented for SP1 
There is good evidence to demonstrate that these processes were implemented as intended (16 scope statements were developed, minutes of progress review meetings exist etc).

In summary, all major components of a strategic planning process were implemented largely as-intended and therefore a degree of confidence can be placed on the outcomes of the impact assessment which follows.

\section{Impact Assessment}

A quasi-experimental design was used for the program impact assessment as proposed by Rossi et al and considers the direct or intended outcomes of SP1 as stated explicitly in the objectives (Rossi et al., 2003). The strongest reflexive control design is to use a time series analysis approach which aims to provide a credible estimate of the impact of SP1 whilst acknowledging that the ideal of a randomized field experiment with a control group is not possible in this instance (i.e. the Institute of Technology Tralee from 2000-2004 without the strategic plan program would be impossible to reconstruct). The impact of SP1 in the DuringSP1 period is estimated at the end of the following time periods

- September 2001 (September 2000 - August 2001)

- September 2002 (September 2001 - August 2002)

- December 2003 (September 2002 - December 2003)

\section{Year One September 2000 - August 2001}

The period September 2000 to September 2001 is particularly interesting. Reviewing the Log of Issues for this period demonstrates that in the first year after the finalization of the plan $n=36$ new issues appeared in the document record compared to an average of $n=20$ each year from 1997-2000. Only $n=4$ of these 36 new issues could not be directly linked to an objective/strategy in SP1. In the first year of implementation of SP1 there was a significantly higher number of issues arising than previous years and more than $80 \%$ of the new issues arising in decision making fora could be directly linked to an objective/strategy of SP1. This demonstrates that SP1 was being actively worked on during this period.

\section{Year Two September 2001 - August 2002}

The progress on each objective was reviewed in October 2002 by the Director and the Strategic Program Office and a progress update document was issued to all staff. Using a combination of the status of each objective in this progress report (the Institute's view of progress), and the objectivity of the independent Log of Issues, evidence of the successful completion of objectives and strategies was sought in the document record. Two objectives which were dependent on Department of Education \& Science capital funding were eliminated from the analysis as the Institute had no control over these objectives. The above table illustrates the status of the remaining 41 objectives in October 2002. One third of objectives (37\%, $\mathrm{n}=15)$ were completed. Two thirds were either in progress $(\mathrm{n}=22,54 \%)$ or had been modified $(\mathrm{n}=3,7 \%)$. One objective had been retired.

\begin{tabular}{|l|c|c|c|c|}
\hline \multirow{3}{*}{$\begin{array}{l}\text { Objectives } \\
\text { Complete }\end{array}$} & \multicolumn{2}{|c|}{ Status 2002 } & \multicolumn{2}{c|}{ Status 2003 } \\
\cline { 2 - 5 } Incomplete/In Progress & 15 & $37 \%$ & 20 & $49 \%$ \\
\cline { 2 - 5 } Modified & 22 & $54 \%$ & 15 & $37 \%$ \\
\cline { 2 - 5 } Retired & 3 & $7 \%$ & 3 & $7 \%$ \\
\cline { 2 - 5 } & 1 & $2 \%$ & 3 & $7 \%$ \\
\cline { 2 - 5 } No Control & 41 & & 41 & \\
\cline { 2 - 5 } & 2 & $5 \%$ & 2 & $5 \%$ \\
\hline
\end{tabular}

Table 3 Status of objectives of SP1 in October 2002 and October 2003

\section{Year Three September 2002 - December 2003}

The impact theory generated for the SP1 stated that outcomes which are a direct result of the program (proximal outcomes) must be evaluated if longer term outcomes (distal outcomes) are to lead to improvements. Distal outcomes (SP1 goals) are dependent on the attainment of proximal outcomes (SP1 
objectives). To present a more accurate picture of the impact of SP1, a more fine-grained analysis of program impact is given in the following table. In the analysis that follows, allowance is made for objectives over which the Institute had no control and objectives which were retired due to changing circumstances/obsolescence. A number of objectives which were incomplete in December 2003 had at least $50 \%$ of the associated strategies completed and credit for this work was given in the following table.

\begin{tabular}{|c|c|c|c|c|c|c|c|c|c|}
\hline \multirow{2}{*}{\begin{tabular}{|l} 
Distal Outcome \\
$\overline{8}$ \\
$\bar{\sigma}$
\end{tabular}} & \multicolumn{6}{|c|}{ Proximal Outcomes } & \multicolumn{3}{|c|}{ Impact Assessment } \\
\hline & 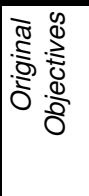 & 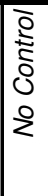 & $\begin{array}{l}\frac{0}{0} \\
\frac{0}{2} \\
\frac{2}{0} \\
0\end{array}$ & 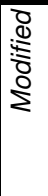 & 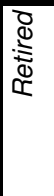 & \begin{tabular}{|l}
$\frac{0}{0}$ \\
$\frac{0}{2}$ \\
$\frac{1}{\delta}$ \\
0 \\
E
\end{tabular} & 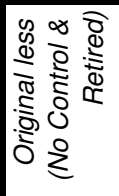 & 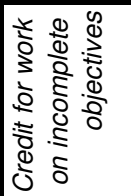 & 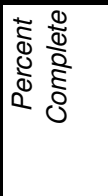 \\
\hline Teaching \& Learning Environment & 10 & 1 & 4 & 0 & 0 & 5 & 9 & 1.25 & $58 \%$ \\
\hline Courses & 2 & 0 & 0 & 1 & 0 & 1 & 2 & 0.5 & $25 \%$ \\
\hline Access & 1 & 0 & 0 & 0 & 0 & 1 & 1 & 0.5 & $50 \%$ \\
\hline Research & 4 & 0 & 2 & 0 & 0 & 2 & 4 & 0.5 & $63 \%$ \\
\hline Entpreneurship & 5 & 0 & 2 & 1 & 1 & 1 & 4 & 0 & $50 \%$ \\
\hline Partnerships & 1 & 0 & 1 & 0 & 0 & 0 & 1 & 0 & $100 \%$ \\
\hline Social \& Cultural & 3 & 0 & 1 & 0 & 0 & 2 & 3 & 0 & $33 \%$ \\
\hline Staff & 4 & 0 & 3 & 1 & 0 & 0 & 4 & 0 & $75 \%$ \\
\hline Physical Resources & 5 & 1 & 3 & 0 & 1 & 0 & 3 & 0 & $100 \%$ \\
\hline Management \& Operations & 3 & 0 & 3 & 0 & 0 & 0 & 3 & 0 & $100 \%$ \\
\hline IS/IT & 3 & 0 & 1 & 0 & 0 & 2 & 3 & 0.5 & $50 \%$ \\
\hline Quality & 1 & 0 & 0 & 0 & 0 & 1 & 1 & 0.5 & $50 \%$ \\
\hline marketing & 1 & 0 & 1 & 0 & 0 & 0 & 1 & 0 & $100 \%$ \\
\hline
\end{tabular}

Table 4 Proximal and Distal Outcomes

A key question is what constitutes effectiveness. December 2003 was originally intended as the half-way point of SP1 (2000-2006). At this point the Institute decided that its operating environment had changed significantly and that a new (or substantially revised) Strategic Plan was necessary. It subsequently moved to a three year planning cycle and a new Strategic Plan for 2004-2007 was developed.

As a broad measure a 'percent complete' of $50 \%$ or more at the mid-point of the plan indicates that SP1 was meeting its targets. If this is accepted as a measure of effectiveness, then SP1 was effective in meeting 11 of 13 goals (distal outcomes). The author recognizes that this is somewhat subjective interpretation. Four goals were fully complete at this point (Partnerships, Management \& Operations, Physical resources and Marketing). SP1 was meeting or exceeding its targets on all goals except Courses and Social \& Cultural. A closer investigation of these goals, and of the work remaining on the Access, Research and Teaching and Learning Environment goal, demonstrates that outstanding items relate to academic issues primarily (student numbers, retention, research funding, course development and delivery mechanisms). When assessed against its stated goals SP1 was effective in meeting its goals. It was significantly less effective on academic goals than in goals with an Institute-wide or central services remit however. This raises questions about its effectiveness in impacting the academic heartland.

\section{Conclusions and Further Research}

It can be concluded with a reasonable degree of certainty that the stimulus for SP1 was an external quality assurance requirement coupled with the identification of the need for a long term planning process to address deficiencies in existing planning structures and processes. This concurs with the findings of Davies and Brennan \& Shah in relation to driving forces for change in Higher Education (Davies, 2004, Brennan and Shah, 1997). As alternative models were not considered and implemented (e.g. Foresight planning) it remains to be seen whether there was a more appropriate planning model for this particular higher education setting. 
All major components of a strategic planning process were implemented largely as-intended and therefore a degree of confidence can be placed on the outcomes of the impact assessment. SP1 captured a considerable percentage of the issues being discussed in the Institute prior to its development, but also incorporated new thinking. In particular it gave central support services a voice in Institute planning. There is some evidence that weaknesses were not being fully addressed in SP1 which concurs with findings in the literature relating to the failure of academics to face up to weaknesses (Drenth and Bernaert 1989; House 1993; Thorn 2003; Davies 2004). There is good evidence that staff engaged with SP1 throughout and that it raised awareness of strategic priorities and influenced decision making, particularly in the first year after it was finalised. One could argue that this in itself was a valuable outcome. Aligning resources, organisational structures and budget plans to meet strategic objectives was problematic however. This concurs with Sallinen's findings in a study of Finnish universities that plans did not provide a basis for changing and restructuring existing activities(Sallinen, Konttinen et al. 1994). The reasons for this may relate to the constraints of the operating environment, inexperience with the process or fundamental mismatch between the strategic planning methodology and the HE environment. A regular progress review system was instigated which assisted in monitoring progress on objectives.

While acknowledging some subjectivity by the author, a threshold of meeting $50 \%$ of targets at the half way point was set as a measure of effectiveness. At that point SP1 was meeting or exceeding its targets on 11 of 13 goals. Work which remained to be completed related primarily to Academic issues. There were particular difficulties in strategically aligning three Schools and SP1 does not appear to have provided a mechanism to address this. It is also worth noting that a significant proportion of development activity in the Schools/Departments was not included in SP1. Although SP1 was effective overall, there are questions in relation to its impact on the academic heartland.

This paper reports on part-findings from a broader study into the effectiveness of strategic planning and self-evaluation programs in Higher Education and their relationship to the Learning Organisation. Further research is currently underway on this topic which includes the development of strategic plans by four academic departments within the School of Science \& Computing in ITT which supported SP1. It is hoped this will provide in-depth insights into the reasons why SP1 was less effective on academic areas.

\section{Bibliography \& References}

Bayenet, B., C. Feola, et al. (2000). "Strategic Management of Universities: Evaluation Policy and Policy Evaluation." Higher Education Management 12(2): 65-80.

Boyle, R. and S. Flemming (2000). The Role of Strategy Statements, Institute of Public Administration.

Brennan, J. and T. Shah (1997). "Quality Assessment, Decision-Making and Institutional Change." Tertiary Education \& Management 3(2): 157-164.

Conway, T., S. Mackay, et al. (1994). "Strategic Planning in Higher Education: Who are the customers?" International Journal of Educational Management 8(6): 29-36.

Davies, J. (2004). Cultural Change in Universities in the Context of Strategic and Quality Initiatives. Strategic Management and Universities' Institutional Development. E. U. Association. Geneva, European University Association: 12-22.

Drenth, P. J. D. and G. F. Bernaert (1989). Improvement of quality of education through internal evaluation (AMOS). Evaluating Higher Education. M. Kogan. London, Jessica Kingsley. 6: 220.

EU (1999). "The Bologna Declaration."

House, E. R. (1993). Professional Evaluation. London, Sage Publications.

Johnson, G. and K. Scholes (2002). Exploring Corporate Strategy, Prentice-Hall, Pearson Education Ltd.

Lau, A. T. T. (1999). "Making Sense of Contemporary Strategic Implementation: Towards A Conceptual Model." Public Administration \& Management: An Interactive Journal 
4(4).

Mintzberg, H. and J. Quinn (1998). Readings in the Strategy Process, Prentice-Hall.

Patton, M. Q. (2002). Qualitative Research \& Evaluation Methods, Sage Publications.

Pidcock, S. (2001). "Strategic Planning in a New university." Journal of Further and Higher Education 25(1).

PMBOK (2004). "Project Management Body of Knowledge." www.pmbok.org.

Pollitt, C. and G. Bouckaert (2004). Public Management Reform, Oxford University Press.

Rowley, D., H. Lujan, et al. (2001). Strategic Change in Colleges and Universities: Planning to Survive and Prosper. San Francisco, Jossey Bass.

Sallinen, A., R. Konttinen, et al. (1994). "Interactive Model of Self Evaluation Quality Assessment at the University of Jyvaskyla - A Pilot Study." Higher Education Management 6(3): 357:375.

Senge, P. (1998). The Leaders New Work: Building Learning Organisations. Readings in the Strategy Process, Prentice-Hall.

Skilbeck, M. (2001). The University Challenged: A Review of International Trends and Issues with Particular Reference to Ireland. Dublin, The Higher Education Authority (Ireland): 155.

Tabatoni, P., J. Davies, et al. (2004). Strategic Management and Universities' Institutional Development, European University Association.

Teichler, U. (2003). Higher Education Research in Europe. The Dialogue between Higher Education Research \& Practice. R. Begg, Kluwer Academic Publishers: 145.

Thorn, R. (2001). "Using Self-Evaluation to Increase Effectiveness in a 'Professional' Organisation - The Case of Higher Education." Administration 49(1): 59-77.

Thorn, R. (2003). Self Study in an Institute of Technology - an evaluation. EAIR Forum 2003 (European Association of Institutional Researchers), University of Limerick, Ireland, EAIR.

Thys-Clement, F. and L. Wilkin (1998). "Strategic Management and Universities: Outcomes of a European Survey." Higher Education Management 10(1): 13-28.

Wilkinson, G. and E. Monkhouse (1994). "Strategic Planning in Public Sector Organisations." Executive Development 7(6): 16-19. 